\title{
A Response to Michael Tite's Paper on Archaeological Collections: Invasive Sampling versus Object Integrity
}

\author{
Nick Merriman \\ Reader in Museum Studies \\ Curator of UCL Museums and Collections \\ Institute of Archaeology, UCL

\section{Introduction} \\ When reading Professor Tite's paper, I found myself in agreement with a great deal \\ of it. He sets out well the criteria which archaeological scientists have to satisfy \\ when they submit requests for invasive sampling, and his understanding of the \\ concerns of curators to minimise damage from sampling, and be informed of the \\ results of the research, is reassuring. He is also sensitive to the need to seek the \\ permission of indigenous peoples before sampling material to which they might have \\ a 'legitimate claim'. I want, though, to draw attention to a few points he has not \\ covered and to respond to his conclusions.
}

\section{Educational and Aesthetic Roles of Objects}

Professor Tite argues that archaeological objects are primarily sources of information "rather than something that must remain totally unchanged after excavation" (Tite, his volume: 1). This, in his view, justifies invasive sampling. However, objects are also vehicles for education and sources of aesthetic inspiration, and in some cases, these understandings will take priority over their role as sources of information. Objects are not all the same, and invasive sampling of, for example, the Portland Vase, is clearly a different matter than taking samples from medieval building material. Nevertheless, it should be possible to contemplate invasive sampling of the Portland Vase as long as the research and subsequent reporting justify it, but only on a very infrequent basis, given that this is not an object that can legitimately be used up in the name of science.

\section{Restoration of Damaged Areas}

A related point that could have been added to the paper is the need for the curator to satisfy her- or himself that the damage caused to objects by invasive sampling methods will be made good as part of the project. I have seen many collections of, for example, prehistoric stone axes where at least half of the specimens have had large slices cut out of them for analysis, rendering them useless for display without further restoration work. This work is not difficult, and many objects on display in museums have been restored; but it should not be left to the museum staff to make good any damage to objects.

\section{Law and Ethics}

One area only touched on briefly in Professor Tite's paper (in relation to indigenous people) is law and ethics. The title of his paper refers to archaeological collections in general, which could be taken to cover scientific work on private collections, as 
well as in public museums. Given the problems caused in the past by some archaeological scientists working on material which turned out to have been illicitly obtained, and the ways in which scientific 'authentication' can be used to enhance the market value of archaeological objects, this seems like an omission. It may have been taken for granted in this paper that analytical work would be undertaken on museum objects, and that this therefore protects the archaeological scientist from any possibility of working on illicitly obtained material. However, it is clear from recent evidence (e.g. Brodie et al. 2000) that some museums do still flout both international legal conventions and general ethical principles by acquiring material that is illegally taken from its country of origin, and/or illegally imported into the museum's country. Until this problem is resolved, it must be incumbent upon archaeological scientists to satisfy themselves that the material which they are requesting to analyse is not illicit and that working on it might be ethically (or even legally) wrong.

\section{Adequacy of Research and Communication of Results}

My main comment on Professor Tite's paper, however, relates to his conclusions, where he regrets that it is becoming more difficult to obtain samples than it was 10 years ago. He feels that some curators place too high an emphasis on object integrity as opposed to invasive sampling, and this, he feels, is hampering archaeological research. From my own experience, this is an incorrect interpretation.

Let me explain this through reference to my own experience as curator of UCL's museums and collections, which include the Petrie Museum of Egyptian Archaeology, and the collections of the Institute of Archaeology. When we began to introduce more co-ordinated management to these collections, one of the things we did was to institute a more rigorous method of assessing applications for destructive analysis. This was because it was realised that a great deal of destructive analysis had been undertaken in the past (as shown by the number of sherds with several holes drilled in them, or other objects with snips or slices taken from them), but no subsequent information about the results of the analysis had been passed back to the museum. In many cases there was a complete absence of documentation as to who had done the work. In other cases the researcher was identifiable, but had not returned the samples or communicated the results in any form. Consequently, many objects had been severely damaged, with no benefit to the museum, and often, as no publication seems to have ensued, no apparent benefit to anyone other than the researcher.

As a result of this unacceptable state of affairs, a Collections Group was formed consisting of the curators of the collections, the Institute of Archaeology's Professor of Archaeological Materials and Technology, and two members of conservation staff. The Group developed a series of procedures for the assessment of requests for destructive analysis, and a form on which to submit requests. The form includes the following terms and conditions:

It is important that the results of analysis are fed back into the records relating to each object. Each request for analysis is therefore granted only on the following conditions: 
Analysis must normally be undertaken within six months and the results reported back to the Institute within three years. This should consist of a copy of the description of the analysis undertaken and the data generated, together with an interpretation of the results.

The Institute of Archaeology or Petrie Museum must be properly credited in any publication.

A copy of any publication or dissertation, or the relevant parts of it, must be supplied to the Museum Manager or Collections Manager.

A copy of any unpublished conservation or analytical report produced must also be supplied.

Normally samples not destroyed during analysis must be returned to the Institute of Archaeology. Samples should be numbered and/or labelled so that a) their relationship to the original object is clear, and b) they can be correctly identified in details of analyses given in the relevant report(s).

Failure to comply with these conditions will prejudice further requests for analysis.

The procedure we have instituted is undoubtedly more time-consuming and bureaucratic than before, but it does now mean that each request is carefully considered in terms of its scientific merit, its sampling strategy, and the reliability of the researcher. While we are anxious to keep damage to a minimum, requests are never turned down on the grounds that the object's integrity should be maintained. Rather, our concern is for good scientific research to take place, and just as important, that the results are communicated back to us so that the museum or collection, and ultimately the wider public, can also benefit from the work undertaken. The existence of clear terms and conditions now means that this is happening (or that those who do not do so are not allowed to undertake further work).

If the amount of invasive sampling has diminished, then I suggest that this is because there was too much work in the past which was ineffective because it was insufficiently considered and unreported. The problem here lay both with the archaeological scientists and with the curators. I would like to feel that we are now all working to a common goal, which is mutually agreed: high quality work which is fed back into the wider archaeological and museum community. We are therefore talking about good research versus poor research here, not invasive sampling versus object integrity.

\section{Reference}

Brodie, N., Doole, J. and Watson, P. 2000. Stealing History: The Illicit Trade in Cultural Material. Cambridge: McDonald Institute for Archaeological Research. 